\title{
Acceptance for Human Papilloma virus vaccines, experience at tertiary care centre of northern india: a hospital-based survey
}

\author{
Manju Lata Verma*, Uma Singh, Prachi Rai, Sabuhi Qureshi
}

Department of Obstetrics and Gynecology, King George’s Medical University, Lucknow, Uttar Pradesh, India

Received: 06 February 2019

Accepted: 11 March 2019

\section{*Correspondence:}

Dr. Manju Lata Verma,

E-mail: gaganmlv@gmail.com

Copyright: (C) the author(s), publisher and licensee Medip Academy. This is an open-access article distributed under the terms of the Creative Commons Attribution Non-Commercial License, which permits unrestricted non-commercial use, distribution, and reproduction in any medium, provided the original work is properly cited.

\section{ABSTRACT}

Background: Acceptance of HPV vaccine is varying widely worldwide in range of 10-70\%. For increasing the acceptability for HPV vaccine, finding the obstacles and catering them diligently is required. The aim of the study was to find out acceptability rate for HPV vaccine in northern India and various obstacles and facilitators affecting acceptance of HPV vaccine.

Methods: A questionnaire based descriptive study was done in the Department of Obstetrics and Gynecology of King George Medical University, Lucknow, Uttar Pradesh, India from June 2016 to June 2017. Questionnaire was filled by doctor after taking face to face interview of individuals. Ethical approval was obtained from the Institutional Ethical Committee of the KGMU, Lucknow, Uttar Pradesh, India. (1689/Ethics/R cell/17) acceptability rate and various facilitators and obstacles for HPV vaccine were studied. For continuous variables mean with standard deviation was used. For categorical variables frequencies and percentages were used. IBM SPSS statistics applied.

Results: A total of 302 cases were face to face interviewed, amongst which, 70 cases $(23 \%)$ showed acceptability and 232 did not accept the vaccine. The most common obstacles were lack of knowledge and high monetary cost being the cause of nonacceptance in $48.3 \%$ and $33.6 \%$ of cases respectively.

Conclusions: Higher level of awareness and knowledge about HPV vaccine and inclusion in government immunization programmed may increase acceptability.

Keywords: Carcinoma cervix, Cervarix, Gardasil, HPV vaccine

\section{INTRODUCTION}

Sexually transmitted human papilloma virus (HPV) infection is the most important causative risk factor for cervical intraepithelial neoplasia (CIN) and invasive cervical cancer. There are over 100 different types of HPV strains but, certain strains of HPV account for about $90 \%$ of high-grade intraepithelial lesions and cancer (HPV16, 18, 31, 33, 35, 39, 45, 51, 52, 56, 58, 59, 68). ${ }^{1}$ Type 16 is the most common HPV found in invasive cervical cancer and in CIN 2 and CIN3. ${ }^{2}$ Because HPV infection is strongly associated with the development of cervical neoplasia, an important step for primary prevention is the provision of prophylactic vaccine to prevent against HPV infection. Two types of HPV vaccines are available at present. These are bivalent (Cervarix), quadrivalent (Gardasil).

These vaccines could prevent development of $70 \%$ cervical cancers worldwide. 9 valent vaccine is $97 \%$ effective in preventing cervical, vaginal and vulvar diseases caused by the five additional HPV types $(31,33$, 45, 52 and 58) that it targets. ${ }^{3}$ However, uptake of HPV vaccine is much lower than other recommended vaccines because of low acceptability. From various studies, the range of acceptability for HPV vaccine worldwide is 
found to be $10-70 \%$. The reasons for low acceptability shown in those studies are lack of knowledge about the vaccine, cost of the vaccine, fear about safety and fear that vaccine may promote increased sexual activity in children. There are certain sociocultural issues associated with the HPV vaccine because it targets a sexually transmitted infection (STI) and primarily targets female adolescents and young adults.

These issues will significantly influence the willingness of health policy makers, health care providers, parents, and adolescent and young girls to receive vaccination. Out of these parental awareness and attitude towards the HPV vaccine are likely to be major determinants of acceptability. ${ }^{4}$ So, this study was aimed to know the acceptance status of HPV vaccine in northern India and various obstacles and facilitators affecting it.

\section{METHODS}

This was a questionnaire based descriptive study, done in the Department of Obstetrics and Gynecology of King George Medical University, Lucknow, Uttar Pradesh, India for a period of 1 year i.e. June 2016 to June 2017. Ethical approval was obtained from the Institutional Ethical Committee of the King George Medical University, Lucknow, Uttar Pradesh, India and approval No. was 1689/Ethics/R.cell-17. Target sample size was 245 from the formula:

\section{$\mathrm{N}=\mathrm{z} 2 \mathrm{p}(1-\mathrm{p}) / \mathrm{e} 2, \mathrm{~N}=$ sample size}

$Z=1.96$ at $5 \%$ alpha error and $20 \%$ beta error

$\mathrm{P}=$ power of study $(80 \%), \mathrm{e}=$ error allowance $(5 \%)$

Cases were selected with following inclusion and exclusion criteria.

\section{Inclusion criteria}

- Individuals giving the consent to participate

- Females of age $>15$ years

- Outdoor patients, their attendants and hospital employees.

\section{Exclusion criteria}

- Individuals not giving the consent to participate.

After taking a written informed consent and fulfilling the set criteria for this study a questionnaire was filled by face to face interview by doctors with cases as selected by the set criteria. The questionnaire covered following points: demographic profile, knowledge about HPV infection and cervical cancer, belief about perceived benefits and barriers to vaccination, perception about whether their daughter might be at risk of HPV infection, parental informational need in relation to HPV vaccination, belief concerning the severity of HPV related diseases including cervical cancer, apprehension regarding side effects of vaccine, and difference of attitude towards vaccination in context of monetary issues. Participants who consented for vaccination for themselves or their daughters were vaccinated. Since, the age group for vaccination was between 9 to 26 years so the cases between the age group of 15-18 years (minor) who were also the part of acceptability study were vaccinated only after getting a written parental consent for vaccination.

\section{RESULTS}

The present study was conducted from June 2016 to June 2017 in the Department of Obstetrics and Gynaecology, KG Medical University, Lucknow, Uttar Pradesh, India with the objective to assess the acceptability and safety of HPV vaccine.

A total of 302 cases were interviewed amongst which 70 cases showed acceptability and 232 did not accept the vaccine. Out of 70 acceptors, 20 cases accepted vaccine for themselves and remaining 50 accepted for their daughters /sisters of which 4 cases had 2 daughters each and both of them got vaccinated so the total number of clients for vaccination were 74. The acceptability of HPV vaccine was highest in the age group 15-20 years (50\%) and lowest in 26-30 years (5\%) as shown in Table 1.

Table 2 explains that there was no significant $(\mathrm{p}>0.05)$ association between acceptability of HPV vaccine and marital status. Single and widow women had better acceptability than married females which was $30.9 \%$ and $66.7 \%$ respectively. There was no significant $(p>0.05)$ association between acceptability of HPV vaccine and religion, although the distribution of cases according to religion was nonhomogeneous (Table 3 ).

Table 4 shows that there was no significant $(p>0.05)$ association between acceptability of HPV vaccine and education. The highest percentage of acceptors were amongst those who had income of Rs $>50,000(75 \%)$ and lowest was in the group Rs. 5000-9999 (4.8\%).

There was significant $(\mathrm{p}<0.05)$ association between acceptability of HPV vaccine and income (Table 5). The percentage of receiving HPV vaccine was higher among who had knowledge about HPV (27.8\%) than no knowledge $(22.2 \%)$. However, there was no significant ( $\mathrm{p}$ $>0.05$ ) association between acceptability of HPV vaccine and knowledge about HPV (Table 6).

There was significant $(\mathrm{p}=0.0001)$ association between acceptability of HPV vaccine and pap screening (Table 7).

Although presence of personal history or history of cancer in relatives does increase the acceptability but there was no statistically significant difference was found (Table 8 and 9). 
Table 1: Correlation of acceptability of HPV vaccine with age.

\begin{tabular}{|c|c|c|c|c|c|c|c|}
\hline \multirow{3}{*}{ Age in years } & \multirow{3}{*}{ No. of cases } & \multicolumn{4}{|c|}{ Accepted HPV vaccine } & \multirow{3}{*}{ OR $(95 \% \mathrm{CI})$} & \multirow{3}{*}{ P-value } \\
\hline & & \multicolumn{2}{|c|}{ Yes } & \multicolumn{2}{|l|}{ No } & & \\
\hline & & No. & $\%$ & No. & $\%$ & & \\
\hline $15-20$ & 10 & 5 & 50.0 & 5 & 50.0 & $1.40(0.25-7.58)$ & 0.69 \\
\hline $21-25$ & 31 & 15 & 48.4 & 16 & 51.6 & $1.31(0.34-5.04)$ & 0.69 \\
\hline $26-30$ & 60 & 3 & 5.0 & 57 & 95.0 & $0.07(0.01-0.37)$ & $0.002 *$ \\
\hline $31-35$ & 83 & 8 & 9.6 & 75 & 90.4 & $0.14(0.03-0.58)$ & $0.006^{*}$ \\
\hline $36-40$ & 80 & 28 & 35.0 & 52 & 65.0 & $0.75(0.21-2.59)$ & 0.65 \\
\hline $41-45$ & 26 & 6 & 23.1 & 20 & 76.9 & $0.42(0.09-2.59)$ & 0.24 \\
\hline $46-50$ & 12 & 5 & 41.7 & 7 & 58.3 & 1.00 (Ref.) & \\
\hline
\end{tabular}

OR-odds ratio, CI-confidence interval, ${ }^{1}$ Univariate binary logistic regression, Ref-Reference, ${ }^{*}$ Significant

Table 2: Effect of marital status on acceptability of HPV vaccine.

\begin{tabular}{|c|c|c|c|c|c|c|c|}
\hline \multirow{3}{*}{ Marital status } & \multirow{3}{*}{ No. of cases } & \multicolumn{4}{|c|}{ Accepted HPV vaccine } & \multirow{3}{*}{ OR $(95 \% \mathrm{CI})$} & \multirow{3}{*}{ P-value ${ }^{1}$} \\
\hline & & \multicolumn{2}{|l|}{ Yes } & \multicolumn{2}{|l|}{ No } & & \\
\hline & & No. & $\%$ & No. & $\%$ & & \\
\hline Married & 240 & 51 & 21.2 & 189 & 78.8 & $0.60(0.31-1.15)$ & 0.12 \\
\hline Cohabit & 4 & 0 & 0.0 & 4 & 100.0 & - & \\
\hline Widow & 3 & 2 & 66.7 & 1 & 33.3 & $4.47(0.37-52.72)$ & 0.23 \\
\hline Single & 55 & 17 & 30.9 & 38 & 69.1 & 1.00 (Ref.) & \\
\hline
\end{tabular}

Table 3: Correlation of acceptability of HPV vaccine with religion.

\begin{tabular}{|c|c|c|c|c|c|c|c|}
\hline \multirow{3}{*}{ Religion } & \multirow{3}{*}{ No. of cases } & \multicolumn{4}{|c|}{ Accepted HPV vaccine } & \multirow{3}{*}{ OR $(95 \% \mathrm{CI})$} & \multirow{3}{*}{ P-value ${ }^{1}$} \\
\hline & & \multicolumn{2}{|c|}{ Yes } & \multicolumn{2}{|l|}{ No } & & \\
\hline & & No. & $\%$ & No. & $\%$ & & \\
\hline Hindu & 267 & 62 & 23.2 & 205 & 76.8 & $1.51(0.17-13.18)$ & 0.70 \\
\hline Muslim & 29 & 7 & 24.1 & 22 & 75.9 & $1.59(0.15-16.01)$ & 0.69 \\
\hline Christian & 6 & 1 & 16.7 & 5 & 83.3 & 1.00 (Ref.) & \\
\hline
\end{tabular}

OR-odds ratio, CI-confidence interval, ${ }^{1}$ Univariate binary logistic regression, Ref-reference

Table 4: Correlation of acceptability of HPV vaccine with education.

\begin{tabular}{|c|c|c|c|c|c|c|c|}
\hline \multirow{3}{*}{ Education } & \multirow{3}{*}{ No. of cases } & \multicolumn{4}{|c|}{ Accepted HPV vaccine } & \multirow{3}{*}{ OR $(95 \% \mathrm{CI})$} & \multirow{3}{*}{ P-value ${ }^{1}$} \\
\hline & & \multicolumn{2}{|l|}{ Yes } & \multicolumn{2}{|l|}{ No } & & \\
\hline & & No. & $\%$ & No. & $\%$ & & \\
\hline Primary or below & 21 & 7 & 33.3 & 14 & 66.7 & $1.07(0.35-3.24)$ & 0.90 \\
\hline High school or below & 29 & 9 & 31.0 & 20 & 69.0 & $0.96(0.35-2.64)$ & 0.94 \\
\hline Intermediate or below & 56 & 9 & 16.1 & 47 & 83.9 & $0.41(0.15-1.06)$ & 0.06 \\
\hline Graduate & 152 & 31 & 20.4 & 121 & 79.6 & $0.54(0.26-1.15)$ & 0.11 \\
\hline Post graduate & 44 & 14 & 31.8 & 30 & 68.2 & 1.00 (Ref.) & \\
\hline
\end{tabular}

OR-Odds ratio, CI-Confidence interval, ${ }^{1}$ Univariate binary logistic regression, Ref-Reference

Table 5: Correlation of acceptability of HPV vaccine with income.

\begin{tabular}{|c|c|c|c|c|c|c|c|}
\hline \multirow{3}{*}{$\begin{array}{l}\text { Income per month in } \\
\text { Rs. }\end{array}$} & \multirow{3}{*}{$\begin{array}{l}\text { No. of } \\
\text { cases }\end{array}$} & \multicolumn{4}{|c|}{ Accepted HPV vaccine } & \multirow{3}{*}{ OR $(95 \% \mathrm{CI})$} & \multirow{3}{*}{ P-value } \\
\hline & & \multicolumn{2}{|l|}{ Yes } & \multicolumn{2}{|l|}{ No } & & \\
\hline & & No. & $\%$ & No. & $\%$ & & \\
\hline$<5000$ & 10 & 1 & 10.0 & 9 & 90.0 & $0.03(0.003-0.42)$ & $0.008 *$ \\
\hline $5000-9999$ & 21 & 1 & 4.8 & 20 & 95.2 & $0.01(0.002-0.18)$ & $0.001 *$ \\
\hline $10,000-14,999$ & 48 & 8 & 16.7 & 40 & 83.3 & $0.06(0.01-0.30)$ & $0.0001 *$ \\
\hline $15,000-19,999$ & 40 & 6 & 15.0 & 34 & 85.0 & $0.05(0.01-0.28)$ & $0.0001 *$ \\
\hline $20,000-29,999$ & 45 & 14 & 31.1 & 31 & 68.9 & $0.15(0.03-0.64)$ & $0.01 *$ \\
\hline $30,000-39,999$ & 83 & 20 & 24.1 & 63 & 75.9 & $0.10(0.02-0.42)$ & $0.002 *$ \\
\hline $40,000-49,999$ & 43 & 11 & 25.6 & 32 & 74.4 & $0.11(0.02-0.50)$ & $0.004 *$ \\
\hline$\geq 50,000$ & 12 & 9 & 75.0 & 3 & 25.0 & 1.00 (Ref.) & \\
\hline
\end{tabular}

OR-odds ratio, CI-Confidence interval, ${ }^{1}$ Univariate binary logistic regression, Ref-Reference, ${ }^{*}$ Significant 
Table 6: Correlation of acceptability of HPV vaccine with knowledge about HPV.

\begin{tabular}{|c|c|c|c|c|c|c|c|}
\hline \multirow{3}{*}{ Knowledge about HPV } & \multirow{3}{*}{ No. of cases } & \multicolumn{4}{|c|}{ Received HPV vaccine } & \multirow{3}{*}{ OR $(95 \% \mathrm{CI})$} & \multirow{3}{*}{ P-value $^{1}$} \\
\hline & & Yes & & No & & & \\
\hline & & No. & $\%$ & No. & $\%$ & & \\
\hline Yes & 54 & 15 & 27.8 & 39 & 72.2 & $1.35(0.69-2.62)$ & 0.37 \\
\hline No & 248 & 55 & 22.2 & 193 & 77.8 & 1.00 (Ref.) & \\
\hline
\end{tabular}

OR-Odds ratio, CI-Confidence interval, ${ }^{1}$ Univariate binary logistic regression, Ref-Reference

Table 7: Correlation of acceptability of HPV vaccine with pap screening in last 3 years.

\begin{tabular}{|c|c|c|c|c|c|c|c|}
\hline \multirow{3}{*}{ PAP screening } & \multirow{3}{*}{ No. of cases } & \multicolumn{4}{|c|}{ Accepted HPV vaccine } & \multirow{3}{*}{ OR $(95 \% \mathrm{CI})$} & \multirow{3}{*}{ P-value ${ }^{1}$} \\
\hline & & \multicolumn{2}{|l|}{ Yes } & \multicolumn{2}{|l|}{ No } & & \\
\hline & & No. & $\%$ & No. & $\%$ & & \\
\hline Yes & 107 & 35 & 32.7 & 72 & 67.3 & $3.29(1.73-6.24)$ & $0.0001 *$ \\
\hline No & 140 & 18 & 12.9 & 122 & 87.1 & 1.00 (Ref.) & \\
\hline
\end{tabular}

OR-Odds ratio, CI-Confidence interval, ${ }^{1}$ Univariate binary logistic regression, Ref-Reference, ${ }^{*}$ Significant

Table 8: Distribution of cases according to history of cancer.

\begin{tabular}{|llll|}
\hline History of cancer & & No. $(\mathbf{n}=302)$ & $\%$ \\
\hline \multirow{2}{*}{ Personal history } & Yes & 8 & 2.6 \\
\cline { 2 - 4 } & No & 294 & 97.4 \\
\hline \multirow{2}{*}{ Relatives/ friends } & Yes & 71 & 23.5 \\
\cline { 2 - 4 } & No & 231 & 76.5 \\
\hline
\end{tabular}

Table 9: Correlation of acceptability of HPV vaccine with history of cancer in self, relatives/friends.

\begin{tabular}{|c|c|c|c|c|c|c|c|c|}
\hline \multirow{3}{*}{ History of cancer } & & \multirow{3}{*}{ No. of patients } & \multicolumn{4}{|c|}{ Accepted HPV vaccine } & \multirow{3}{*}{ OR $(95 \% \mathrm{CI})$} & \multirow{3}{*}{ P-value ${ }^{1}$} \\
\hline & & & \multicolumn{2}{|l|}{ Yes } & \multicolumn{2}{|l|}{ No } & & \\
\hline & & & No. & $\%$ & No. & $\%$ & & \\
\hline \multirow{2}{*}{$\begin{array}{l}\text { History of cancer in } \\
\text { relatives/friends }\end{array}$} & Yes & 71 & 19 & 26.8 & 52 & 73.2 & $1.29(0.70-2.37)$ & 0.41 \\
\hline & No & 231 & 51 & 22.1 & 180 & 77.9 & 1.00 (Ref.) & \\
\hline \multirow{2}{*}{ Personal history } & Yes & 8 & 2 & 25.0 & 6 & 75.0 & $1.10(0.21-5.61)$ & 0.90 \\
\hline & No & 294 & 68 & 23.1 & 226 & 76.9 & & \\
\hline
\end{tabular}

OR-Odds ratio, CI-Confidence interval, ${ }^{1}$ Univariate binary logistic regression, Ref-Reference.

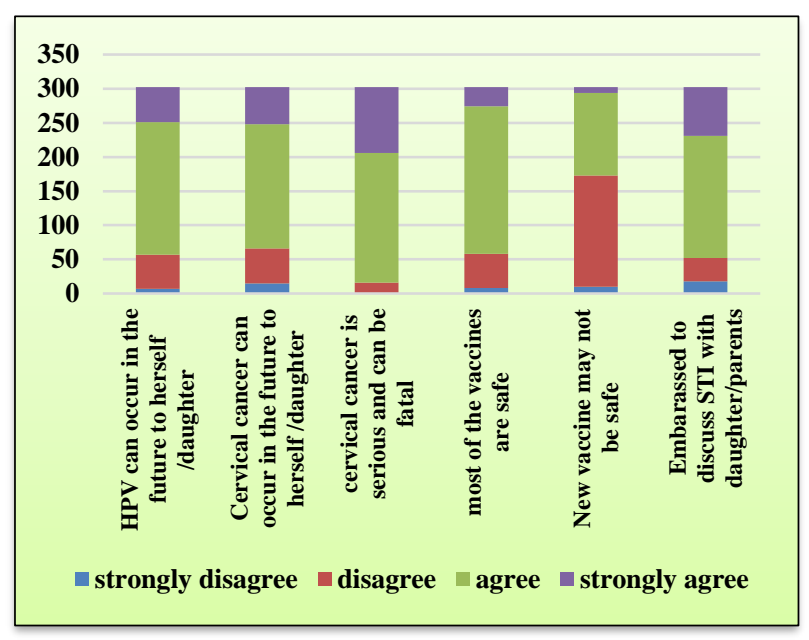

Figure 1: Perception about HPV vaccine and cervical cancer.
Knowledge about HPV infection and HPV vaccine related to cervical cancer were assessed by different questions as depicted in (Table 10 and 11).

The knowledge about HPV was in $17.9 \%$ cases. Out of them, majority reported that people do not know when they have HPV being true $(85.2 \%)$. Majority of patients also reported that HPV can be found in most of sexually active women and HPV infection can be cleared by treatment being true $(70.4 \%)$. However, use of condom can completely prevent HPV being true was reported by $48.1 \%$ of patients. Cervical cancer is mainly caused by HPV infection was truly reported by $64.8 \%$ patients and some types of HPV can cause genital warts was truly reported by $63 \%$ patients. The knowledge about HPV vaccine for cervical cancer was among $48.3 \%$ cases. Out of them, 51.4 reported that HPV vaccination can $100 \%$ prevent cervical cancer being true. 
Table 10: Distribution of cases according to knowledge about HPV infection.

\begin{tabular}{|c|c|c|}
\hline Knowledge about HPV infection & No. & $\%$ \\
\hline Knowledge & $\mathrm{n}=30$ & \\
\hline Yes & 54 & 17.9 \\
\hline No & 248 & 82.1 \\
\hline $\begin{array}{l}\text { People do not know when they } \\
\text { have HPV }\end{array}$ & $\mathrm{n}=54$ & \\
\hline True & 46 & 85.2 \\
\hline False & 2 & 3.7 \\
\hline Unknown & 6 & 11.1 \\
\hline \multicolumn{3}{|c|}{ HPV can be found in most of sexually active women } \\
\hline True & 38 & 70.4 \\
\hline False & 9 & 16.7 \\
\hline Unknown & 7 & 13.0 \\
\hline \multicolumn{3}{|c|}{ HPV infection can be cleared by treatment } \\
\hline True & 38 & 70.4 \\
\hline False & 4 & 7.4 \\
\hline Unknown & 12 & 22.2 \\
\hline \multicolumn{3}{|c|}{ Use of condom can completely prevent HPV } \\
\hline True & 26 & 48.1 \\
\hline False & 9 & 16.7 \\
\hline Unknown & 19 & 35.2 \\
\hline \multicolumn{3}{|c|}{ Cervical cancer is mainly caused by HPV infection } \\
\hline True & 35 & 64.8 \\
\hline False & 1 & 1.9 \\
\hline Unknown & 18 & 33.3 \\
\hline \multicolumn{3}{|c|}{ Some types of HPV can cause genital warts } \\
\hline True & 34 & 63.0 \\
\hline False & 2 & 3.7 \\
\hline Unknown & 18 & 33.3 \\
\hline
\end{tabular}

Table 11: Assessment of knowledge about HPV vaccine for cervical cancer in cases $(n=302)$.

\begin{tabular}{|c|c|c|}
\hline \multirow{2}{*}{$\begin{array}{l}\text { Knowledge about HPV vaccine } \\
\text { for cervical cancer }\end{array}$} & No. & $\%$ \\
\hline & \multicolumn{2}{|l|}{$\mathrm{n}=302$} \\
\hline Yes & 146 & 48.3 \\
\hline No & 156 & 51.7 \\
\hline Knowledge about & \multicolumn{2}{|l|}{$\mathrm{n}=146$} \\
\hline \multicolumn{3}{|c|}{ HPV vaccination can $100 \%$ prevent cervical cancer } \\
\hline True & 75 & 51.4 \\
\hline False & 19 & 13.0 \\
\hline Unknown & 52 & 35.6 \\
\hline \multicolumn{3}{|c|}{$\begin{array}{l}\text { It's not necessary to have routine Pap smear after } \\
\text { receiving HPV vaccination }\end{array}$} \\
\hline True & 39 & 26.7 \\
\hline False & 33 & 22.6 \\
\hline Unknown & 74 & 50.7 \\
\hline \multicolumn{3}{|c|}{ HPV vaccine can prevent all types of HPV infection } \\
\hline Strongly disagree & 6 & 4.1 \\
\hline Disagree & 33 & 22.6 \\
\hline Agree & 102 & 69.9 \\
\hline Strongly agree & 5 & 3.4 \\
\hline
\end{tabular}

About one fourth of cases reported that it's not necessary to have routine Pap smear after receiving HPV vaccination $(26.7 \%)$ whereas about half of the cases $(50.7 \%)$ had no idea about it. HPV vaccine can prevent all types of HPV infection was agreed by $69.9 \%$ cases.

Table 12: Reasons of receiving HPV vaccine amongst acceptors.

\begin{tabular}{|c|c|c|}
\hline Reasons of receiving HPV vaccine & No. & $\%$ \\
\hline $\begin{array}{l}\text { Believed HPV vaccine can prevent } \\
\text { cervical cancer }\end{array}$ & 14 & 20 \\
\hline $\begin{array}{l}\text { Believed HPV vaccine can prevent } \\
\text { genital warts }\end{array}$ & 2 & 2.8 \\
\hline Vaccine is good for health & 1 & 1.4 \\
\hline Doctor recommended & 36 & 51.4 \\
\hline Relatives/friends recommended & 17 & 24.3 \\
\hline
\end{tabular}

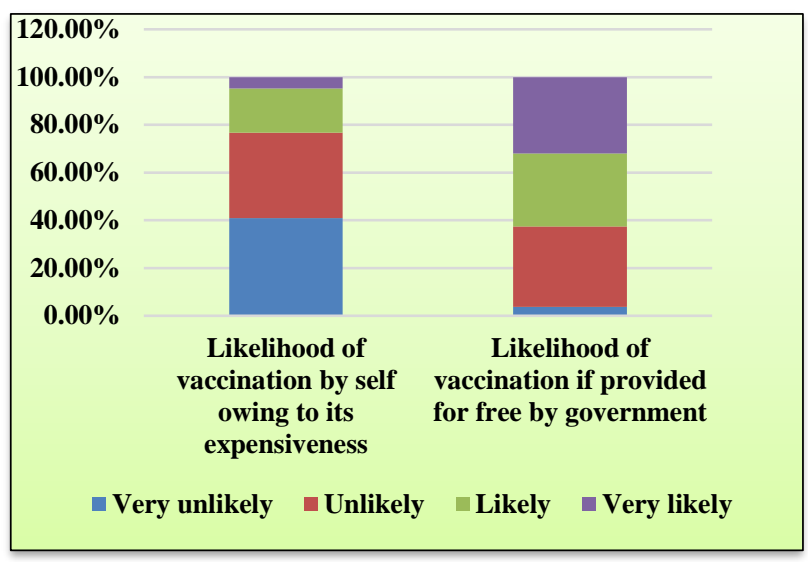

Figure 2: Attitude towards vaccination considering monetary factor.

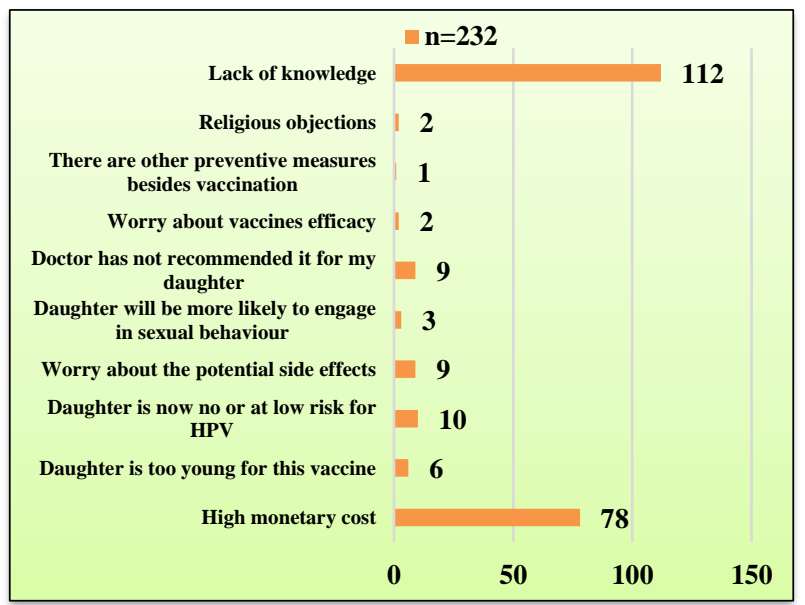

Figure 3: Reasons for not receiving the HPV vaccine.

More than half of cases agreed that HPV infection might happen in the future to themselves or their daughters $(51.4 \%)$ followed by friends' recommendation are the most common facilitators for acceptance. (Figure 1) explains about perception of HPV vaccine and cervical 
cancer and (Figure 2 and 3), shows that high monetary cost is a big obstacle for accepting the HPV vaccine.

\section{DISCUSSION}

In this study, 302 cases were interviewed, out of which 70 cases accepted the HPV vaccine. So, the acceptability rate in this study was $23 \%$. However total no of vaccinated cases was 74 because 4 cases had 2 daughters each and both of them got vaccinated. The HPV vaccine was given from 9 to 26 years age group. Out of 74 girls who were vaccinated, 54 were between the age of 9 to 14 years and the remaining 20 were between 15 to 26 years. The cases from age group of 15-26 years were directly interviewed for acceptability of HPV vaccine (client acceptability). Total no of cases in age group of 15-26 years in present study were 41 so client acceptability rate was $48.8 \%$ (20/41). For the cases from age group of 9-14 years, parents were interviewed for acceptability (parental acceptability). Out of 261 cases only 50 had given acceptance for vaccination for their daughters so parental acceptability in present study was only $19.2 \%(50 / 261)$. The acceptability was much lower than many earlier studies, for example Constantine et al, reported $75 \%$ acceptability for HPV vaccination in a study conducted in California. ${ }^{5}$ Another study was done in Sweden by Dahlstrom et al, to assess the attitude to HPV vaccination among parents of children aged 12-15 years and it was found that only $76 \%$ of the parents were willing to vaccinate their child if the vaccine was for free and $63 \%$ were willing to vaccinate even if it comes with a cost. ${ }^{6}$ Likewise, Kwan TT et al, reported $88 \%$ acceptability for HPV vaccination in Chinese women. Montgomery MP et al, conducted a survey among women in Karnataka for assessment of knowledge and acceptability of HPV vaccine and reported that $46 \%$ of women were willing to get vaccinated. ${ }^{7,8}$ This is higher than the acceptability rate of the present study. The reason behind this is because, the awareness rate of women in Karnataka about HPV infection was higher $(36 \%)$ than the present study which is only $17.9 \%$. The age group of participants in present study was from 15 to 50 years. $54 \%$ were in the age group of 31-40 years, $19.8 \%$ belonged to $26-30$ years. $13.6 \%$ belonged to $15-25$ years i.e. the age group also eligible for vaccination. In present study authors did not find statistically significant correlation between acceptability and age, although a trend towards higher acceptability of HPV vaccine was seen in the age group of $15-20$ years $(50 \%)$. Lowest acceptability was seen in 26-30 years age group (5\%). The higher acceptability in adolescent age group could be because of more awareness about sexually transmitted infection acquired from schools and colleges. In contrast to present study HPV vaccine acceptability is seen to be generally high in women over 26 years in other studies. Weiss TW et al, conducted a study to find attitudes towards HPV vaccination among US women aged 27 to 45 years and found that $71.1 \%$ were likely to get vaccinated if the HPV vaccine were offered in the future to women in their age group. ${ }^{9}$ However, some studies have shown that the younger women have higher acceptability, for example Kahn JA et al, conducted a study on sexually active females between 13-26 years of age and found that 5\% of the cases have already received the vaccine and $66 \%$ intended to receive the vaccine. ${ }^{10}$ However, the higher acceptability in this group of sexually active people was due to perceived severity of HPV, sexually transmitted disease history, insurance coverage and fewer practical barriers to vaccination. In present study, a majority of cases $(88.4 \%)$ were Hindus. Muslims comprised of only $9.6 \%$ cases and Christians were hardly $2 \%$. The percentage of acceptance of HPV vaccine was almost similar in Hindus (23.2\%) and Muslims (24.1\%). However, the sample was not homogeneously distributed in terms of religion. Therefore, there was no statistically significant effect of religion on acceptability in present study could be noted. Though not well studied, religion may play an even greater role when it comes to influencing vaccine decision-making for sexually transmitted infections like HPV than for other vaccines. A study by Constantine NA et al, and Jerman P et al, reported that infrequent religious service attenders had higher acceptability for HPV vaccination. ${ }^{5}$ On the contrary, there are several studies that show religion has a positive impact on HPV vaccination, for example Lefkowitz ES et al, in reported that young women who adhered more closely to their religion's sexual teachings were more likely to be vaccinated. ${ }^{11}$ In a study conducted by Hussain AN et al, Muslim students had very less knowledge on HPV infection and its relation to cervical cancer as compared to Hindu students. ${ }^{12}$ In present study nearly half of the cases were graduate $(50.3 \%)$, followed by cases who were intermediate or below $(18.5 \%)$, post graduate $(14.6 \%)$, high school $(9.6 \%)$ and primary $(7 \%)$. Though there was no statistically significant effect of education on acceptability, a trend of higher acceptability was seen in lower educated cases. This could be explained by the fact that most of this cases were those who either attended the OPD or were hospital employees. So, these people had more awareness about HPV and its vaccine by the posters or by the awareness campaigns held in this hospital. A study in Sweden by Ostensson $\mathrm{E}$ et al, also showed higher vaccination coverage against HPV infection if either of the parents was university-educated. ${ }^{13}$ In contrast to the abovementioned studies, other group of studies also reported paradoxical outcome of higher parental education on HPV vaccination. For example, Feiring $\mathrm{B}$ et al, in Norway reported that maternal education was negatively associated with HPV vaccination. ${ }^{14}$ Another study in Canada by Ogilvie GS et al, also reported to have inverse relation between parental education and acceptance to HPV vaccine. ${ }^{15}$ These findings of inverse association were explained by the fact that educated parents tend to undertake own internet research making them likely to end up in websites with unclear and confusing information on HPV infection or even website. Acceptability of HPV vaccine was seen to be more in the higher income group. Similar to present study Belani $\mathrm{HK}$ et al, in a study done in Bangalore concluded that 
high cost of the HPV vaccine acts as a barrier to vaccination $(53 \%) .{ }^{16}$ Because of the present high cost of the vaccine the affordability and accessibility of these vaccines is a major concern for a mass vaccination program in developing countries like India. But several studies found that there was no association between income and acceptance and major deterrents found in their study were concern about too many vaccinations, vaccine side effects, worry about increasing promiscuity. ${ }^{17,18}$

In present study, only $17.9 \%$ cases had ever heard about HPV. That too, majority of subjects mistakenly thought that HPV could be cleared by treatment and use of condom can completely prevent HPV. Present study result is consistent with other studies in India that showed low level of cervical cancer and HPV knowledge even in medical students Mehta $\mathrm{S}$ et al. ${ }^{19}$ Also there is lack of knowledge in paramedical staff workers in India as shown in a study by Chawla PC et al, who found that only $47 \%$ of respondents recommended HPV vaccine. ${ }^{20}$

Similarly, another study among college students aged 1835 years in Ghana, done by Molowku PN et al, noted very low awareness (7.9\%) regarding the link between HPV and cervical cancer. ${ }^{21}$ The poor knowledge of HPV infection may result in reduced perceived risk and severity of HPV infection, thereby accounting for the low acceptability rate of HPV vaccination in present study. This seems to be evident by another study done by Bernard J G et al. ${ }^{22}$ An HPV information sheet was provided to parents, but it was found that, although it seemed to increase knowledge about HPV, but the increased knowledge had little effect on the acceptability of HPV vaccine by parents for their children. Instead, attitudes and life experiences seemed to be more important factors influencing HPV vaccine acceptability among parents. But in contrast, a study by Donadiki EM et al, in Greece among female university and technological institute students (age 18-26 years) reported that $59.1 \%$ students are aware of HPV vaccine and this high level of knowledge is positively associated with vaccine uptake. ${ }^{23,24}$ Another study from Mexico among college students, aged 17-25 years, done by Vogtmann E et al, showed that most of the students have heard of HPV, although they had limited knowledge about the causal relation with virus and the preventive strategies. ${ }^{25}$ In this study, it was observed that only 8 cases $(2.6 \%)$ had personal history of cancer and 2 out of them (25\%) accepted the HPV vaccine for their daughters. Similarly, 71 i.e. $(23.5 \%)$ cases were reported to have history of cancer in relatives or friends, out of which only $26.8 \%$ cases showed acceptability for HPV vaccine. The percentage of accepting HPV vaccine was higher among whom the personal history of cancer was present. Similarly, a trend of higher acceptability was noticed among whom the history of cancer in relatives/friends was present. However, there was no significant association between acceptability of HPV vaccine and history of cancer in self, relatives or friends.
Various studies have shown that people with history of genital cancer in family had shown greater acceptability for HPV vaccine. In a study conducted by Di Guisuppe et al, it was seen that participants with history of cervical cancer in self, family or friends reported higher intention to vaccinate themselves or their daughters against HPV. ${ }^{26}$ Al Moustafa et al, reported that genital cancer history in the family significantly increased awareness for the HPV vaccine but, there was no increase in the acceptability of the vaccine. ${ }^{27}$ This is consistent with present study findings that there was no effect of history of cancer on the acceptability of HPV vaccine. This could be explained by the fact that in present scenario still the knowledge of cervical cancer and its correlation with STI especially HPV is lacking. Other reason could be that sometimes, the parents do not communicate such illness in the family to their children. The most commonly reported reason for accepting the HPV vaccine in the present study were doctor's recommendations (51.4\%). This was consistent with the study done in India by Basu $\mathrm{P}$ et al, and Mittal $\mathrm{S}$ et al, which indicated that healthcare personnel's recommendations play an integral role in shaping the attitude towards HPV vaccination. ${ }^{28}$ Ylitalo $\mathrm{KR}$ et al, also reported that health care providers recommendation is an important facilitator for enhancing the acceptability of HPV vaccine. ${ }^{29}$ A small population of parents $(3.8 \%)$ had mentioned that doctor did not recommend their daughter to be vaccinated against HPV because their daughters were still too young to receive it. Another reason for not recommending HPV vaccine could be that physicians were uncomfortable in discussing sexually transmitted infection related vaccine with parents. This is consistent with a study on quality of physician communication about HPV vaccine by Hswen Yet al, who reported that approximately $34 \%$ of the physicians reported anticipating an uncomfortable discussion about HPV vaccine. ${ }^{30}$ It may be likely that the knowledge and awareness of HPV vaccine is varied among health care providers and a minority may have inadequate knowledge. Relatives and friend's recommendation (17\%) were quoted as the second most common reason to accept HPV vaccine. This is explained by the fact that a person is more receptive to advice from their near and dear ones rather than from a third party. Only $14 \%$ of the cases reported to accept the HPV vaccine due to the belief that HPV vaccine can prevent genital infections. That HPV vaccine can prevent cervical cancer was reported by $2 \%$ of the cases as the reason to accept HPV vaccine. Not surprisingly, the top one reason of mothers for not accepting the vaccine was lack of knowledge about HPV vaccine and its role in prevention of cervical cancer. This is consistent with our findings that out of $48.3 \%$ of cases HPV, $69.9 \%$ of cases misunderstood that HPV vaccine could prevent all types of HPV. $50.7 \%$ of cases had no idea about the necessity of pap smear after receiving HPV vaccine. Similar, to present study findings a study published in 2008 by Kwan TT et al, among Chinese adolescent girls in Hong Kong demonstrated that participants knowledge on cervical cancer was poor. ${ }^{7}$ In present study only $56.3 \%$ of 
the cases had knowledge about pap smear for cervical cancer screening. Nearly half of the cases who have heard about pap smear incorrectly answered that HPV can be detected in pap smear. High monetary cost has been identified as the most significant barrier for HPV vaccination consistent with other studies Kwan TT et al, particularly in those places without financial support from the government. ${ }^{7}$ The acceptability rate for HPV vaccine markedly differs by the cost as found in present study that the willingness to vaccinate against HPV was $62.5 \%$ if provided for free by government of India which decreased to $23.2 \%$ if they had to pay by themselves. It is very consistent with the acceptability rate of $23 \%$ as found in present study. So, the major hindrance to vaccination is probably the high monetary cost in our setting after lack of knowledge. Other common reasons reported were similar to previous findings from several studies for example, the worry about the potential side effects daughter being too young for HPV vaccine and daughter at no or low risk for HPV.

\section{Funding: No funding sources}

Conflict of interest: None declared

Ethical approval: The study was approved by the Institutional Ethics Committee KGMU, Lucknow, UP, India (No. 1689/Ethics/ R cell/17)

\section{REFERENCES}

1. Lorincz AT, Reid R, Jenson AB, Greenberg MD, Lancaster W, Kurman RJ. Human papillomavirus infection of the cervix: relative risk associations of 15 common anogenital types. Obstet Gynecol. 1992;79(3):328-7.

2. Bauer HM, Ting Y, Greer CE, Chambers JC, Tashiro CJ, Chimera J, et al. Genital human papillomavirus infection in female university students as determined by a PCR-based method. JAMA. 1991;265(4):472-7.

3. Chatterjee A. The next generation of HPV vaccines: nonavalent vaccine V503 on the horizon. Expert Review Vaccines. 2014;13(11):1279-90.

4. Nigam A, Saxena P, Acharya AS, Mishra A, Batra S. HPV vaccination in India: critical appraisal. ISRN Obstet Gynecol. 2014;2014.

5. Constantine NA, Jerman P. Acceptance of human papillomavirus vaccination among Californian parents of daughters: a representative statewide analysis. J Adolesc Health. 2007;40(2):108-15.

6. Dahlström LA, Tran TN, Lundholm C, Young C, Sundström K, Sparén P. Attitudes to HPV vaccination among parents of children aged 12-15 years-A population-based survey in Sweden. Int $\mathrm{J}$ Cancer. 2010;126(2):500-7.

7. Kwan TT, Chan KK, Yip AM, Tam KF, Cheung AN, Lo SS, et al. Acceptability of human papillomavirus vaccination among Chinese women: concerns and implications. BJOG: An Int J Obstetr Gynaecol. 2009 1;116(4):501-10.

8. Montgomery MP, Dune T, Shetty PK, Shetty AK. Knowledge and acceptability of human papillomavirus vaccination and cervical cancer screening among women in Karnataka, India. J Canc Edu. 2015;30(1):130-7.

9. Weiss TW, Rosenthal SL, Zimet GD. Attitudes toward HPV vaccination among women aged 27 to 45. ISRN Obstet Gynecol. 2011;2011.

10. Kahn JA, Rosenthal SL, Jin Y, Huang B, Namakydoust A, Zimet GD. Rates of human papillomavirus vaccination, attitudes about vaccination, and human papillomavirus prevalence in young women. Obstetr Gynecol. 2008;111(5):110310 .

11. Lefkowitz ES, Kelly KM, Vasilenko SA, Maggs JL. Correlates of human papillomavirus vaccination among female university students. Women Health. 2014;54(6):487-501.

12. Hussain AN, Alkhenizan A, McWalter P, Qazi N, Alshmassi A, Farooqi S, et al. Attitudes and perceptions towards HPV vaccination among young women in Saudi Arabia. J Family Comm Med. 2016;23(3):145.

13. Östensson E, Fröberg M, Leval A, Hellström AC, Bäcklund M, Zethraeus N, et al. Cost of preventing, managing, and treating human papillomavirus (HPV)-related diseases in Sweden before the introduction of quadrivalent HPV vaccination. PloS One. 2015;10(9):e0139062.

14. Feiring B, Laake I, Molden T, Cappelen I, Håberg SE, Magnus $\mathrm{P}$, et al. Do parental education and income matter? A nationwide register-based study on HPV vaccine uptake in the school-based immunisation programme in Norway. BMJ open. 2015;5(5):e006422.

15. Ogilvie GS, Cook DA, Taylor DL, Rank C, Kan L, $\mathrm{Yu}$ A, et al. Population-based evaluation of typespecific HPV prevalence among women in British Columbia, Canada. Vaccine. 2013;31(7):1129-33.

16. Belani HK, Sekar P, Guhaniyogi R, Abraham A, Bohjanen PR, Bohjanen K. Human papillomavirus vaccine acceptance among young men in Bangalore, India. Int J Dermat. 2014;53(11):e486-91.

17. Brabin L, Roberts SA, Farzaneh F, Kitchener HC. Future acceptance of adolescent human papillomavirus vaccination: a survey of parental attitudes. Vaccine. 2006;24(16):3087-94.

18. Marlow LA, Waller J, Wardle J. Parental attitudes to pre-pubertal HPV vaccination. Vaccine. 2007;25(11):1945-52.

19. Mehta S, Rajaram S, Goel G, Goel N. Awareness about human papilloma virus and its vaccine among medical students. Indian journal of community medicine: official publication of Indian Assoc Preven Social Med. 2013;38(2):92.

20. Chawla PC, Chawla A, Chaudhary S. Knowledge, attitude and practice on human papillomavirus vaccination: A cross-sectional study among healthcare providers. Indian J Med Res. 2016;144(5):741.

21. Molokwu J, Penaranda E, Flores S, Shokar NK. Evaluation of the effect of a promotora-led 
educational intervention on cervical cancer and human papillomavirus knowledge among predominantly Hispanic Primary Care patients on the US-Mexico border. J Canc Edu. 2016;31(4):742-8.

22. Barnard JG, Dempsey AF, Brewer SE, Pyrzanowski J, Mazzoni SE, O'leary ST. Facilitators and barriers to the use of standing orders for vaccination in obstetrics and gynecology settings. Am J Obstet Gynecol. 2017;216(1):69-e1.

23. Donadiki EM, Jiménez-García R, Hernández-Barrera V, Carrasco-Garrido P, Lopez de Andres A, JimenezTrujillo I, et al. Knowledge of the HPV vaccine and its association with vaccine uptake among female higher-education students in Greece. Human Vaccines Immunotherap. 2013;9(2):300-5.

24. Donadiki EM, Jiménez-García R, Hernández-Barrera V, Carrasco-Garrido P, de Andrés AL, Velonakis EG. Human papillomavirus vaccination coverage among Greek higher education female students and predictors of vaccine uptake. Vaccine. 2012;30(49):6967-0.

25. Vogtmann E, Harlow SD, Valdez AC, Valdez JC, Ponce EL. HPV knowledge in Mexican college students: implications for intervention programmes. Health Social Care Community. 2011;19(2):148-57.

26. Di Giuseppe G, Abbate R, Liguori G, Albano L, Angelillo IF. Human papillomavirus and vaccination: knowledge, attitudes, and behavioural intention in adolescents and young women in Italy. British $\mathbf{J}$ Canc. 2008;99(2):225.

27. Al Moustafa AE, Al-Awadhi R, Missaoui N, Adam I, Durusoy R, Ghabreau L, et al. Human papillomaviruses-related cancers: Presence and prevention strategies in the Middle East and North African Regions. Human Vaccines Immunotherap. 2014;10(7):1812-1.

28. Basu P, Mittal S. Acceptability of human papillomavirus vaccine among the urban, affluent and educated parents of young girls residing in Kolkata, Eastern India. J Obstet Gynaecol Res. 2011;37(5):393-401.

29. Ylitalo KR, Lee H, Mehta NK. Health care provider recommendation, human papillomavirus vaccination, and race/ethnicity in the US National Immunization Survey. Am J Public Health. 2013;103(1):164-9.

30. Hswen Y, Gilkey MB, Rimer BK, Brewer NT. Improving physician recommendations for HPV vaccination: the role of professional organizations. Sexually Transmitted Dis. 2017;44(1):42.

Cite this article as: Verma ML, Singh U, Rai P, Qureshi S. Acceptance for Human Papilloma virus vaccines, experience at tertiary care centre of northern india: a hospital-based survey. Int J Reprod Contracept Obstet Gynecol 2019;8:1907-15. 